\title{
BMJ Global Health Access to personal protective equipment in exposed healthcare workers and COVID-19 illness, severity, symptoms and duration: a population-based case- control study in six countries
}

\author{
Hyunju Kim, ${ }^{1,2}$ Sheila Hegde, ${ }^{3,4}$ Christine LaFiura, ${ }^{5}$ Madhunika Raghavan, ${ }^{5}$ \\ Nancy Sun, ${ }^{6}$ Susan Cheng, ${ }^{6}$ Casey M Rebholz, ${ }^{1,2}$ Sara B Seidelmann ${ }^{4,7,8}$
}

To cite: Kim H, Hegde S, LaFiura $\mathrm{C}$, et al. Access to personal protective equipment in exposed healthcare workers and COVID-19 illness, severity, symptoms and duration: a population-based case-control study in six countries. BMJ Global Health 2021;6:e004611. doi:10.1136/ bmjgh-2020-004611

Handling editor Seye Abimbola

- Additional material is published online only. To view please visit the journal online (http://dx.doi.org/10.1136/ bmjgh-2020-004611).

Received 1 December 2020 Revised 5 January 2021 Accepted 14 January 2021

Check for updates

\section{(c) Author(s) (or their} employer(s)) 2021. Re-use permitted under CC BY-NC. No commercial re-use. See rights and permissions. Published by BMJ.

For numbered affiliations see end of article.

\section{Correspondence to} Dr Sara B Seidelmann; smb88@caa.columbia.edu

\section{ABSTRACT}

Background Despite the widespread implementation of personal protective equipment (PPE) in the COVID-19 pandemic, there are surprisingly few studies of its impact. To assess the risk, severity and duration of COVID-19 in relation to access to PPE in at-risk healthcare workers (HCWs). Methods From 17 July to 25 September 2020, at-risk physicians and nurses registered as a provider in the Survey Healthcare Globus network in six countries (the UK, Germany, France, Italy, Spain and USA) were identified based on adult medical specialties with frequent and close contact with patients with COVID-19. Exposed HCWs completed a detailed questionnaire including demographics, medical, social and lifestyle factors. COVID-19 cases were defined as COVID-19 symptoms (fever, cough, fatigue, loss of taste or smell) and asymptomatic COVID-19 test positive cases.

Results Among 2884 exposed HCWs ( $94 \%$ medical doctors and $6 \%$ nurses or physician assistants), there were 514 reports of COVID-19 illness and 54 asymptomatic COVID-19 test positive cases. COVID-19 risk was significantly associated with close contact with COVID-19 cases both inside and outside the workplace, number of work shifts and hours worked per week. Limited access to PPE compared with access to a fresh mask, gown and gloves and face shield with each patient encounter was associated with a 2.2-fold to 22-fold increased risk of reporting COVID-19 symptoms $(p<0.0001)$, a pattern consistent across all six countries. Further, limited access to PPE was associated with symptom duration greater than 2 weeks and the presence of moderate to severe symptoms such as difficulty breathing, abnormal chest X-ray, low oxygen saturations, respiratory distress and acute lung injury.

Conclusion In six countries, less access to PPE was strongly associated with both increased risk of reporting COVID-19 illness as well as more prolonged and severe disease course in frontline HCWs.

\section{INTRODUCTION}

Healthcare workers (HCWs) have been disproportionally affected by the COVID-19 pandemic, caused by the novel coronavirus,

\section{Key questions}

What is already known?

- Healthcare workers (HCWs) have been disproportionally affected by the COVID-19 pandemic, caused by the novel coronavirus, SARS-CoV-2.

- Despite the widespread implementation of personal protective equipment (PPE) in the COVID-19 pandemic, there are surprisingly few studies of its impact.

- More evidence is needed to understand the effect of PPE on COVID-19 disease transmission and disease course.

\section{What are the new findings?}

- Limited access to PPE compared with access to a fresh mask, gown and gloves and face shield with each patient encounter was associated with a significantly increased risk of reporting COVID-19 symptoms in the UK, Germany, France, Italy, Spain and USA

- Limited access to PPE was associated with increased severity of the disease and the presence of moderate to severe symptoms such as difficulty breathing, abnormal chest X-ray, low oxygen saturations, respiratory distress and acute lung injury.

What do the new findings imply?

- Our findings highlight the need for excellent access to PPE in frontline HCWs.

- Greater access to PPE was associated with shorter and less severe illness, supporting the idea that even when PPE fails, it may reduce the dose of virus taken in by the mask-wearer and offer protection from severe illness.

SARS-CoV-2. ${ }^{1}$ Given their high frequency of exposure, HCWs who treat adult patients with COVID-19 illness in emergency rooms and hospitals may be particularly susceptible to contracting the infection. ${ }^{2}$ Despite the widespread implementation of personal 
protective equipment (PPE) during the COVID-19 pandemic, there are surprisingly few studies of its impact. $^{13}$

To date, only a few observational studies in HCWs and non-HCWs and one randomised controlled trial in nonHCWs have been published on the effectiveness of PPE and COVID-19 infection. A meta-analysis on face mask use, eye protection and viral infections found that face masks were associated with an $82 \%$ lower risk and eye protection was associated with a $75 \%$ lower risk of SARS, Middle East respiratory syndrome, and COVID-19 collectively. However, the meta-analysis included only three studies of COVID-19 and facemasks, two of which were small with 10 events or fewer, and no studies were included for COVID-19 and eye protection. ${ }^{4}$ In a large US academic medical centre, requiring mask wearing for all employees and patients resulted in a significant decrease in transmission between patients and HCWs and among HCWs. ${ }^{5}$ Other centres have not been as fortunate to have sufficient PPE with HCWs resorting to reusing single use PPE or developing makeshift alternatives. ${ }^{6}$ Meta-analyses of the prevention of infectious diseases with PPE have suggested its benefit but called for more work in the field. ${ }^{7}$ Since publication of these studies, one randomised controlled trial in Denmark examined whether a recommendation to wear a mask reduced incident SAR-CoV-2 infection among mask wearers in the general community. ${ }^{8}$ This trial found that the incidence of SAR-CoV-2 infection did not differ for participants who were recommended to wear masks compared with those who were not. However, recommendations to wear masks does not necessarily indicate that participants actually wore masks and behaviours may have differed among mask wearers vs non-mask wearers. Given the limited evidence base, more studies are needed to understand the effect of PPE on COVID-19 disease transmission and disease course.

The objectives of this study were to investigate the associations between workplace risk factors, particularly access to PPE and the risk, severity and duration of COVID-19 among at-risk physicians and nurses from six countries (the UK, Germany, France, Italy, Spain and USA). We leveraged the network of a global healthcare survey firm (Survey Healthcare Globus (SHG)) to access physicians and nurses throughout the UK and Europe in order to gather information about their personal experiences in the COVID-19 pandemic. Historically, large physician panels have been established to aid in healthcare market research. These panels enable market research agencies and consultancies to carry out research on behalf of pharmaceutical and medical device companies so that they may make more informed decisions. In this case, instead of giving their insights to companies to help them make health outcomes decisions, physicians consented to share their own data-demographics, medical, social and lifestyle factors-in order to aid an academic research study of COVID-19.

\section{METHODS}

\section{Study design, setting and population}

The study design is a population-based case-control study. From the SHG network of 1.5 million physicians and HCWs in the USA or European Union registered as a provider for the purposes of participating in market research studies, we identified at risk physicians and nurses based on medical specialties known to have a high contact frequency with COVID-19 patients (emergency medicine, critical care, subspecialties of internal medicine). Recruitment goals for each country were predetermined, based on the network of SHG, with larger relative size in the USA versus European Union. We used a casecontrol design because we expected COVID-19 cases to be rarer than controls. COVID-19 was emerging during the study design phase (April 2020); thus, the prevalence of COVID-19 was much lower than at the time of publication (1.8 million cumulative cases in April vs 82 million cumulative cases in December 2020 globally). ${ }^{9}$ We defined cases and controls as participants were being enrolled into the study and found much slower enrolment of cases compared with controls, consistent with our expectation. To ensure comparability between cases and controls, we limited this study to inpatient settings and specific medical specialties who would have been expected to have high frequency of exposure to patients with COVID-19.

The study was open from 17 July 2020 through 25 September 2020. Before completing a questionnaire, participants were screened for self-reported SARS-CoV-2 exposure, specialty, practice setting, COVID-19 symptoms and COVID-19 PCR or antibody results. Participants were unable to enter the questionnaire if they had infrequent exposure ( $<5 \%$ of time) to patients with COVID-19 unless they also had COVID-19 illness or positive test results implying significant exposure, or if they were not from predetermined high-risk fields or practice settings. We selected $5 \%$ of time because the prevalence of patients with COVID-19 was low during the study design phase, and to screen for HCWs who have had contact with patients with COVID-19. As a quality control measure, participants were unable to enter the questionnaire if inconsistencies were detected between symptom severity and description. For instance, responses were considered inconsistent if participants rated their symptom severity as 'severe' (respiratory distress (respiratory rate $\geq 30$ times/min), low oxygen saturation (SpO2) $<93 \%$ at rest) or acute lung injury (partial pressure of oxygen $\left(\mathrm{PaO}_{2}\right) /$ (fraction of inspired oxygen) $\mathrm{FiO}_{2} \leq 300 \mathrm{~mm} \mathrm{Hg}$ )), but participants did not select any of these specific symptoms to describe their experience with COVID-19. Seven thousand three hundred forty-four participants were prescreened to enter the study and 4460 were not eligible and were terminated before the questionnaire was administered. Two thousand four hundred and eighty-two did not have close contact or proximity with patients with COVID-19 at work (or not sure), 631 were physicians in fields other than those predetermined as high risk, 559 
nurses were not in a high-risk setting (hospital-based), 181 participants did not consent, 57 had inconsistent responses between symptoms and disease severity, and 550 were over quota for negative/asymptomatic controls.

Questionnaires were administered to 2884 exposed HCWs throughout the USA, UK, Germany, France, Italy and Spain. The questionnaire was completed online. It consisted of approximately 100 questions including demographics, medical history, social history, medication and supplements, a food frequency questionnaire, sleep habits, stress and physical activity. SHG offered participants a small honorarium for participation. Questionnaires and informed consent were translated and administered in the primary language for each country (English-USA and UK, Spanish-Spain, FrenchFrance, Italian-Italy and German-Germany).

\section{Patient and public involvement}

Due to the rapid spread of COVID-19 and the need to disseminate the results of the study as quickly as possible, patients were not involved in the recruitment, design, conduct or interpretation of the study or development of research questions or outcomes measures.

\section{Ascertainment of COVID-19 cases and controls}

HCWs were considered to be COVID-19 cases based on their report of COVID-19 diagnosis and symptoms with an affirmative response to the following question: 'Since exposure, have you personally experienced symptoms consistent with a diagnosis of COVID-19 (fever, coughing, fatigue, loss of taste or smell)?' Symptoms and symptom severity were recorded in subsequent questions. HCWs were considered to be COVID-19 controls if they if they did not experience symptoms consistent with a diagnosis of COVID-19 (were asymptomatic) and did not report a positive SARS-CoV2 PCR or antibody test. We used both symptoms and positive SARS-CoV2 PCR or antibody test to define cases because many HCWs in Europe would not have had timely access to testing in the earlier phase of the pandemic. Further, testing negative for SARS-CoV2 antibodies does not necessarily indicate that an individual, in fact, did not have COVID-19.

\section{Exposures}

Participants reported the amount of time they were in close proximity to patients with COVID-19 by answering the question 'On a typical shift during the COVID-19 pandemic, how frequently were you in close proximity to patients or others with COVID-19?' Participants had six options to choose, ranging from $<5 \%$ of time to $>75 \%$ of time. Participants reported whether they had been in close contact with a patient with COVID-19 outside the workplace ('Have you been in close contact with anyone outside of your workplace with a confirmed diagnosis of COVID-19?'). Similarly, participants reported whether they had been in close contact with suspected or confirmed patients with COVID-19 inside the workplace while not wearing PPE ('Have you been in close contact with any suspected or confirmed case of COVID-19 inside your workplace while not wearing COVID-recommended PPE?'). For these two questions, participants could answer 'yes', 'no' or 'not sure'.

Participants reported the number of shifts per week, number of hours per shift, work hours per week, and whether they had been in a room of a confirmed COVID-19 patient during continuous positive airway pressure (CPAP), bilevel positive airway pressure (BiPAP), nebulisation, intubation or cardiopulmonary resuscitation (CPR). Participants were asked to describe their access to PPE (masks, face shields, gowns and gloves) by choosing the following options: "non-existent (no access to at least one of the following: masks, face shields, gowns, and gloves)', 'poor (little access to masks, face shields, gowns, and gloves)', 'basic (access to at least one daily mask, face shield, gown, and gloves)', 'good (I had access to a change of mask, gown, and gloves if soiled as well as a face shield)', 'excellent (I had access to a fresh mask, gown, and gloves every time that I entered a new patient room as well as a face shield)'. A copy of the questionnaire is available as online supplemental file 1 .

\section{Statistical analyses}

Categorical data were reported as percent frequencies and compared by $\chi^{2}$ or Fischer exact tests. Mean and SD were employed to display normally distributed continuous variables. Due to the limited number of cases, we pooled data from all six countries in our analyses, except for the analyses on access to PPE and COVID-19-like illnesses. First, we assessed the association of COVID-19 exposures with COVID-19 like illness using multivariable logistic regression models, adjusting for age, gender and country. Second, we examined the association between workplace risk factors and COVID-19 like illness. In addition to age, gender and country, models were further adjusted for access to PPE and close exposure to a COVID-19 case outside the workplace. Third, we evaluated the association between access to PPE and COVID-19 like illness in all six countries and stratified by each country. When we combined data from all six countries, we considered age, gender, country, specialty, provider type, close exposure inside the workplace without PPE and close exposure outside the workplace as covariates. Lastly, the association between COVID-19 risk factors and duration and severity of illness was analysed with multivariable linear regression models controlling for potential confounders such as: age, sex, geographical region, medical history and COVID-19 exposure outside of the workplace. A sensitivity analysis was carried out evaluating the association of COVID-19 risk factors after limiting cases to those who tested positive by antibody or PCR.

\section{RESULTS}

The study population consisted according to COVID-19 illness are shown in table 1 . The study population 
Table 1 Baseline characteristics of physicians, nurses or physician assistants exposed to patients with COVID-19 in the workplace.

\begin{tabular}{|c|c|c|c|}
\hline & $\begin{array}{l}\text { Controls } \\
n=2316\end{array}$ & $\begin{array}{l}\text { Cases } \\
n=568\end{array}$ & $P$ value \\
\hline Gender, N (\%) & & & 0.63 \\
\hline Female & $640(28 \%)$ & $154(27 \%)$ & \\
\hline Male & $1656(72 \%)$ & $410(72 \%)$ & \\
\hline Other & $1(0 \%)$ & $1(0 \%)$ & \\
\hline Prefer not to say & $19(1 \%)$ & $3(1 \%)$ & \\
\hline Age (mean $\pm S D)$ & $48 \pm 10$ & $47 \pm 10$ & 0.11 \\
\hline $\begin{array}{l}\text { Significant, close } \\
\text { exposure to } \\
\text { COVID-19 }\end{array}$ & $100 \%$ & $100 \%$ & . \\
\hline $\begin{array}{l}\text { Experienced } \\
\text { symptoms of } \\
\text { COVID-19 }\end{array}$ & $0(0 \%)$ & $514(90 \%)$ & . \\
\hline $\begin{array}{l}\text { Number of days of } \\
\text { symptoms }\end{array}$ & 0 & $11 \pm 13$ & . \\
\hline Country & & & $<0.001$ \\
\hline France & $208(9 \%)$ & $48(8 \%)$ & \\
\hline Germany & $233(10 \%)$ & $46(8 \%)$ & \\
\hline Italy & $359(16 \%)$ & $74(13 \%)$ & \\
\hline Spain & $382(16 \%)$ & $146(26 \%)$ & \\
\hline UK & $233(10 \%)$ & $94(17 \%)$ & \\
\hline USA & 901 (39\%) & $160(28 \%)$ & \\
\hline Race/ethnicity & & & 0.46 \\
\hline White & 1792 (77\%) & $426(75 \%)$ & \\
\hline $\begin{array}{l}\text { Any mixed/multiple } \\
\text { ethnic background }\end{array}$ & $121(5 \%)$ & $41(7 \%)$ & \\
\hline Asian & $271(12 \%)$ & $65(11 \%)$ & \\
\hline African & $36(2 \%)$ & $12(2 \%)$ & \\
\hline Other & $29(1 \%)$ & $7(1 \%)$ & \\
\hline Prefer not to say & $67(3 \%)$ & $17(3 \%)$ & \\
\hline Smoking & & & 0.80 \\
\hline Current smoker & $110(5 \%)$ & $24(4 \%)$ & \\
\hline Former smoker & 341 (15\%) & $86(15 \%)$ & \\
\hline Never smoked & 1865 (81\%) & $458(81 \%)$ & \\
\hline Medical doctor & 2187 (94\%) & $548(96 \%)$ & 0.048 \\
\hline $\begin{array}{l}\text { Nurse/nurse } \\
\text { practitioner/ } \\
\text { physician assistant }\end{array}$ & $129(6 \%)$ & $20(4 \%)$ & \\
\hline Physician specialty & & & 0.10 \\
\hline Other & $10(0 \%)$ & $2(0 \%)$ & \\
\hline $\begin{array}{l}\text { Allergy and } \\
\text { immunology }\end{array}$ & $25(1 \%)$ & $4(1 \%)$ & \\
\hline Cardiology & 227 (10\%) & $54(10 \%)$ & \\
\hline Critical care & $230(10 \%)$ & $52(9 \%)$ & \\
\hline Emergency medicine & $512(22 \%)$ & $91(16 \%)$ & \\
\hline $\begin{array}{l}\text { Endocrinology, } \\
\text { diabetes, and } \\
\text { metabolism }\end{array}$ & $74(3 \%)$ & $24(4 \%)$ & \\
\hline
\end{tabular}

Continued
Table 1 Continued

\begin{tabular}{llll}
\hline & $\begin{array}{l}\text { Controls } \\
\mathbf{n = 2 3 1 6}\end{array}$ & $\begin{array}{l}\text { Cases } \\
\mathbf{n}=568\end{array}$ & P value \\
\hline Gastroenterology & $77(3 \%)$ & $17(3 \%)$ & \\
Haematology & $85(4 \%)$ & $27(5 \%)$ & \\
Infectious disease & $82(4 \%)$ & $18(3 \%)$ & \\
Internal medicine & $322(14 \%)$ & $111(20 \%)$ & \\
Nephrology & $38(2 \%)$ & $15(3 \%)$ & \\
Neurology & $82(4 \%)$ & $25(5 \%)$ & \\
Pulmonology & $354(15 \%)$ & $76(13 \%)$ & \\
Rheumatology & $69(3 \%)$ & $32(6 \%)$ &
\end{tabular}

Nurse/NP/PA practice setting 0.36

Emergency room $22(17 \%) \quad 2(10 \%)$

Intensive care unit $45(35 \%) \quad 5(25 \%)$

(ICU)

Other hospital- $\quad 62(48 \%) \quad 13(65 \%)$

based department

\begin{tabular}{|c|c|c|c|}
\hline \multicolumn{4}{|l|}{ Medical conditions } \\
\hline Pre-diabetes & $38(1.6 \%)$ & $16(2.8 \%)$ & 0.06 \\
\hline Diabetes & $70(3.0 \%)$ & $26(4.6 \%)$ & 0.06 \\
\hline High cholesterol & $320(13.8 \%)$ & $76(13.4 \%)$ & 0.79 \\
\hline Cancer & $326(14.1 \%)$ & $78(13.7 \%)$ & 0.83 \\
\hline $\begin{array}{l}\text { Coronary heart } \\
\text { disease }\end{array}$ & $59(2.5 \%)$ & $11(1.9 \%)$ & 0.4 \\
\hline Heart failure & $31(1.3 \%)$ & $13(2.3 \%)$ & 0.1 \\
\hline Prior lung disease & $8(0.3 \%)$ & $2(0.4 \%)$ & 0.98 \\
\hline Prior lung infection & $9(0.4 \%)$ & $4(0.7 \%)$ & 0.31 \\
\hline Asthma & $34(1.5 \%)$ & $6(1.1 \%)$ & 0.45 \\
\hline Overweight & $218(9.4 \%)$ & $69(12.1 \%)$ & 0.05 \\
\hline Autoimmune disease & $307(13.3 \%)$ & $81(14.3 \%)$ & 0.53 \\
\hline $\begin{array}{l}\text { COVID-19 PCR or } \\
\text { antibody test }\end{array}$ & & & $<0.001$ \\
\hline $\begin{array}{l}\text { No-I did not a get } \\
\text { a test }\end{array}$ & $695(30 \%)$ & $53(9 \%)$ & \\
\hline $\begin{array}{l}\text { No-I did not have } \\
\text { access to the test }\end{array}$ & $69(3 \%)$ & $32(6 \%)$ & \\
\hline $\begin{array}{l}\text { Yes - I tested } \\
\text { negative }\end{array}$ & $1552(67 \%)$ & $185(33 \%)$ & \\
\hline $\begin{array}{l}\text { Yes-I tested } \\
\text { positive }\end{array}$ & $0(0 \%)$ & $298(52 \%)$ & \\
\hline $\begin{array}{l}\text { Test for influenza or } \\
\text { respiratory viruses }\end{array}$ & other & & $<0.001$ \\
\hline $\begin{array}{l}\text { No-I did not a get } \\
\text { a test }\end{array}$ & $1876(81 \%)$ & $418(74 \%)$ & \\
\hline $\begin{array}{l}\text { No-I did not have } \\
\text { access to the test }\end{array}$ & $205(9 \%)$ & $50(9 \%)$ & \\
\hline $\begin{array}{l}\text { Yes }- \text { I tested } \\
\text { negative }\end{array}$ & $225(10 \%)$ & $79(14 \%)$ & \\
\hline $\begin{array}{l}\text { Yes - I tested } \\
\text { positive }\end{array}$ & $10(0 \%)$ & $21(4 \%)$ & \\
\hline
\end{tabular}

Cases are defined as self-reported COVID-19 like illness or a positive COVID-19 test in the absence of symptoms. NP, nurse practitioner; PA, physician assistant. 
comprised primarily of male physicians with an average age in their late forties (table 1). By study design, all study participants had close exposure to COVID-19 cases, and were similar in terms of sex, age, race/ethnicity, smoking, and medical specialty by cases and controls. COVID-19 cases experienced symptoms with an average duration of 11 days. HCWs were represented from France, Germany, UK, Italy, Spain and USA in ascending order. The study population was primarily composed of self-reported white individuals; report of COVID-19 illness did not differ by race/ethnicity. Physicians were selected for fields that had frequent and close exposure to COVID-19 patients: emergency medicine, critical care, general internal medicine and its subspecialties and neurology. Nurse practitioners, nurses and physicians' assistants were hospital based or worked in the intensive care unit or emergency room. COVID-19 case group was slightly more likely to have pre-diabetes and diabetes, or to be overweight, although these differences were not statistically significant. The majority of the study population received testing for SARS-CoV2 viral infection by PCR or antibody test. Sixtyseven per cent of the asymptomatic control group tested negative while $33 \%$ did not have access or did not get a test. Fifty-two per cent of the COVID-19 case group was positive for PCR or antibody test, 33\% tested negative and $15 \%$ did not have access or did not get a test. Most of the study population was not tested for other respiratory viruses. Twenty-one cases tested positive for influenza or another respiratory virus, nineteen of which also had a positive COVID-19 PCR or antibody test.

The odds of reporting COVID-19 was greater with more frequent contact with patients with COVID-19 in the workplace ( $\mathrm{P}$ trend $<0.0001)$ (table 2 ). Close contact with any suspected or confirmed case of COVID-19 inside the workplace while not wearing COVID-19 recommended PPE was associated with greater odds of reporting COVID-19 illness $(\mathrm{p}<0.0001)$. Furthermore, close contact with anyone outside the workplace with a confirmed diagnosis of COVID-19 was associated with greater odds of reporting COVID-19 illness $(\mathrm{p}<0.0001)$.

The number of shifts per week but not number of work hours per shift was significantly associated with reporting COVID-19 illness $(p=0.028)$ with $7 \%$ greater odds of COVID-19 illness per shift (table 3). Weekly work hours were also associated with increased risk of reporting COVID-19 illness after adjusting for age, gender, country, access to PPE and close exposure to a COVID-19 case outside the workplace. High-risk procedures such as being in a room with a patient during CPAP or BiPAP, nebulisation, intubation or CPR were not associated with reporting COVID-19 illness after adjusting for access to PPE and exposure to COVID-19 cases outside of the work setting.

Access to PPE in exposed frontline HCWs and risk of reporting COVID-19 illness are displayed in figure 1 and online supplemental table 1 . In all countries, odds of reporting COVID-19 illness was nearly eightfold greater with non-existent access to PPE, threefold greater with poor access to PPE, twofold greater with basic access to PPE and 1.5-fold greater with good access to PPE, versus those with excellent access ( $p$ trend $<0.0001$ ) (figure 1; online supplemental table 1). In general, these associations were statistically significant in the USA, UK, Spain and Italy but did not reach statistical significance in Germany and France independently.

Table 2 COVID-19 exposures and ORs of COVID-19 like illness (self-reported COVID-19 like illness or a positive COVID-19 test) in exposed healthcare workers adjusting for age, gender, and country

\begin{tabular}{|c|c|c|}
\hline & OR (95\% Cl) & $P$ value \\
\hline Contact with COVID-19 patients in the workplace: & & $<0.0001^{*}$ \\
\hline Not very frequent $(5 \%-10 \%$ of my time) & Ref & - \\
\hline Somewhat frequent $(11 \%-25 \%$ of my time) & 1.13 (0.84 to 1.52$)$ & 0.4 \\
\hline Frequent $(26 \%-50 \%$ of my time $)$ & 1.40 (1.03 to 1.89$)$ & 0.031 \\
\hline Very frequent (51\%-75\% of my time) & 1.69 (1.22 to 2.33$)$ & 0.0014 \\
\hline Continuous (greater than $75 \%$ of my time) & 1.65 (1.19 to 2.28$)$ & 0.0026 \\
\hline \multicolumn{3}{|c|}{$\begin{array}{l}\text { Close contact with any suspected or confirmed case of COVID-19 } \\
\text { inside the workplace while not wearing COVID-recommended PPE }\end{array}$} \\
\hline No & Ref & - \\
\hline Not sure & $1.53(1.18$ to 1.98$)$ & 0.0015 \\
\hline Yes & 1.65 (1.34 to 2.04$)$ & $<0.0001$ \\
\hline \multicolumn{3}{|c|}{$\begin{array}{l}\text { Close contact with anyone outside the workplace with a confirmed } \\
\text { diagnosis of COVID-19 }\end{array}$} \\
\hline No & Ref & - \\
\hline Not sure & 0.86 (0.67 to 1.11$)$ & 0.26 \\
\hline Yes & $1.87(1.49$ to 2.33$)$ & $<0.0001$ \\
\hline
\end{tabular}

*This value is $p$ trend. 
Table 3 Workplace risk factors and ORs of COVID-19 like illness (self-reported COVID-19 like illness or a positive COVID-19 test) in exposed healthcare workers adjusting for age, gender and country and model 2 age, gender, country, access to personal protective equipment (PPE) and close exposure to a COVID-19 case outside the workplace

\begin{tabular}{|c|c|c|c|c|}
\hline & Model 1* & $P$ value & Model $2 \dagger$ & $P$ value \\
\hline Number of shifts per week & $1.08(1.02-1.15)$ & 0.009 & $1.07(1.01-1.14)$ & 0.028 \\
\hline Number of work hours per shift & $1.00(0.95-1.04)$ & 0.14 & $1.01(0.96-1.05)$ & 0.80 \\
\hline Work hours per week & $1.01(1.00-1.01)$ & 0.015 & $1.01(1.00-1.01)$ & 0.018 \\
\hline \multicolumn{5}{|c|}{ Been in the room of a patient with confirmed COVID-19 during any of the following: } \\
\hline CPAP or BiPAP & $0.78(0.64-0.95)$ & 0.012 & $0.86(0.70-1.04)$ & 0.125 \\
\hline Nebulisation & $0.91(0.74-1.12)$ & 0.37 & $0.89(0.72-1.10)$ & 0.295 \\
\hline Intubation & $0.72(0.58-0.89)$ & 0.003 & $0.83(0.67-1.03)$ & 0.086 \\
\hline CPR & $0.91(0.71-1.15)$ & 0.42 & $0.98(0.77-1.24)$ & 0.89 \\
\hline None of the above & $1.24(1.02-1.51)$ & 0.032 & $1.14(0.94-1.39)$ & 0.19 \\
\hline
\end{tabular}

*Model 1 adjusted for age, gender and country.

†Model 2 adjusted for age, gender, country, access to personal protective equipment (PPE) and close exposure to a COVID-19 case outside the workplace.

BiPAP, bilevel positive airway pressure; CPAP, continuous positive airway pressure; CPR, cardiopulmonary resuscitation.

HCWs were more likely to report greater than 14 days of symptoms $(\mathrm{p}=0.004)$ and moderate-to-severe symptoms $(\mathrm{p}=0.006)$ with poor access to PPE relative to excellent access to PPE even after multivariable adjustment including comorbidities (table 4). Reporting symptoms of nausea or vomiting $(\mathrm{p}=0.029)$, sore throat or headache ( $\mathrm{p}=0.039)$, and fever or chills $(\mathrm{p}=0.049)$ were significantly associated with less access to PPE. Respiratory symptoms such as shortness of breath or difficulty breathing $(\mathrm{p}=0.021)$, abnormal chest X-ray, low oxygen saturation, respiratory distress or acute lung injury $(\mathrm{p}=0.036)$ were also significantly associated with less access to PPE among

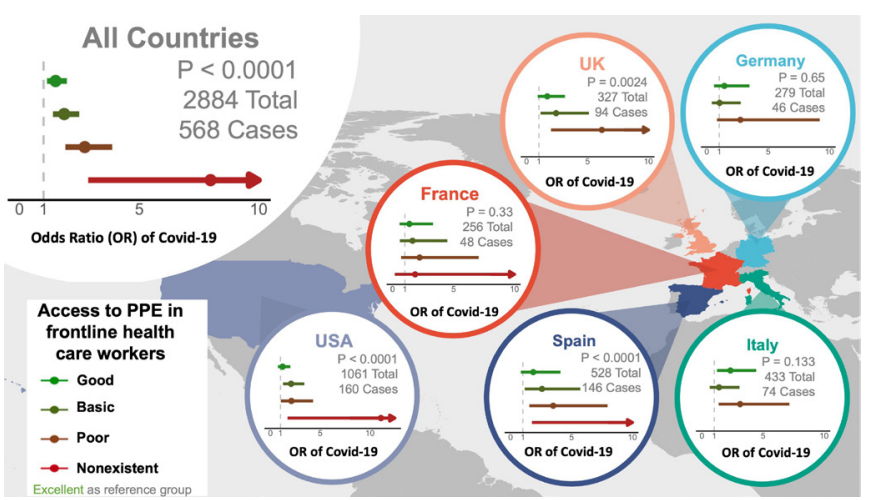

Figure 1 Access to personal protective equipment (PPE) and ORs) of COVID-19 like illness (self-reported COVID-19 like illness or a positive COVID-19 test) in exposed healthcare workers. The dots represent ORs and the lines represents $95 \% \mathrm{Cls}$. Model for all countries ( $n=2884 ; n=568$ cases) was adjusted for age, gender, country, specialty, provider type and closer exposure to a COVID-19 case inside the workplace without PPE and close exposure outside of the workplace. Models for each country was adjusted for age, gender, close exposure to a COVID-19 case inside the workplace without PPE and close exposure outside of the workplace. $P$ values represent $p$ for trend. Point estimates and $95 \%$ Cls are available in online supplemental table 1.
HCWs. For analyses on number of days, severity and symptoms of COVID-19, we did not stratify by country due to limited number of cases in each country.

The main study findings were unchanged in a sensitivity analysis limited to cases who tested positive for SARs-CoV-2 by PCR or antibody testing ( $\mathrm{n}=298,11.4 \%)$ and this did not change the main study findings (online supplemental tables 2-5). There was a statically significant association between access to PPE and odds of positive COVID-19 test (PCR or antibody) as well ( $p$ trend $<0.0001$, online supplemental table 4 ).

\section{DISCUSSION}

\section{Statement of principal findings}

In a large population of exposed physicians and nurses living in six different countries in Europe and the USA, risk of reporting COVID-19 was significantly associated with close contact with COVID-19 cases both inside and outside the workplace, number of work shifts and hours worked per week. Limited access to PPE was associated with a significantly increased risk of reporting COVID-19 across all six countries. Limited access to PPE was associated with symptom duration of greater than 2 weeks and moderate-to-severe symptoms such as nausea or vomiting, fever or chills, difficulty breathing or shortness of breath, abnormal chest X-ray, low oxygen saturations, respiratory distress or acute lung injury.

Importantly, this study shows a strong, consistent relationship between access to PPE and COVID-19 risk in exposed physicians and nurses across multiple countries. Our findings incrementally add to prior studies which examined the associations between PPE and COVID-19 in a single country with sample sizes ranging from 37 to $5442^{10-12}$ and are in line with several other observational studies that support the importance of PPE in stopping the transmission of COVID-19. ${ }^{41314}$ At-risk providers 
Table 4 Number of days, severity and type of COVID-19 symptoms in association with access to personal protective equipment (PPE) in exposed healthcare workers

\begin{tabular}{|c|c|c|c|c|}
\hline & $\begin{array}{l}\text { OR access to PPE } \\
\text { good versus excellent }\end{array}$ & $\begin{array}{l}\text { OR access to PPE } \\
\text { basic versus excellent }\end{array}$ & $\begin{array}{l}\text { OR access to PPE poor } \\
\text { versus excellent }\end{array}$ & P trend \\
\hline$>14$ days of symptoms & $1.26(0.62-2.55)$ & $1.76(0.86-3.61)$ & $2.39(1.10-5.22)$ & 0.0044 \\
\hline \multicolumn{5}{|l|}{ Specific COVID-19 symptoms: } \\
\hline Fatigue and muscle aches & $1.53(0.79-2.93)$ & $2.07(1.00-4.30)$ & $0.97(0.46-2.08)$ & 0.86 \\
\hline Diarrhoea & $1.88(0.94-3.73)$ & $2.04(1.01-4.12)$ & $1.79(0.82-3.89)$ & 0.28 \\
\hline Nausea or vomiting & $1.18(0.53-2.64)$ & $2.53(1.14-5.59)$ & $2.10(0.87-5.07)$ & 0.029 \\
\hline Sore throat or headache & $2.40(1.37-4.18)$ & $2.92(1.62-5.27)$ & $2.15(1.11-4.14)$ & 0.039 \\
\hline Fever or chills & $1.47(0.85-2.56)$ & $1.49(0.83-2.65)$ & $2.25(1.16-4.39)$ & 0.049 \\
\hline
\end{tabular}

${ }^{*}$ Adjusted for age, gender, country, diabetes, pre-diabetes, coronary artery disease, overweight, asthma and high-risk exposure to an individual with COVID-19 outside of the workplace ( $n=568$ total).

†Poor access to PPE was described as 'little access to masks, face shields, gowns, and gloves'. Basic access was described as 'access to at least one daily mask, face shield, gown, and gloves'. Good access to PPE was described as 'I had access to a change of mask, gown, and gloves if soiled as well as a face shield'. Excellent access to PPE was described as 'I had access to a fresh mask, gown, and gloves every time that I entered a new patient room as well as a face shield'.

who had no access to either a mask, face shield, gown or gloves were eight times more likely to report COVID19. Risk decreased with some access to more than one of those items and decreased further with daily change of mask, gown and gloves and access to a face shield. Risk was lowest for those providers that could change their mask gown and gloves every time that they entered a new patient room. Risk of COVID-19 may be lower for HCWs with excellent access to PPE, given that PPE can provide a physical protection which can block the spread of respiratory droplets from infected individuals. ${ }^{3} \mathrm{PPE}$, such as surgical masks, can also can reduce virus shedding into the environment. ${ }^{15}$

Notably, to the best of our knowledge, this is the largest study thus far to find that greater access to PPE not only reduced the risk of contracting COVID-19, but was associated with reduced severity of the disease in frontline HCWs. Those HCW who reported limited access to masks, gowns, gloves and face shields had a nearly 2.5fold higher odds of COVID-19 symptoms lasting for more than 14 days and 3.5-fold higher odds of reporting moderate-to-severe symptoms versus those with fresh PPE for each patient encounter. It is possible that this observation is due to a reduced SARS-CoV-2 inoculum as access to PPE was greater, potentially resulting in reduced disease severity. Previously, scientists have hypothesised that universal mask wearing reduces the dose of the virus for the mask-wearer, resulting in milder disease course or asymptomatic infection. Depending on the type of mask, they filter out most but not all viral particles. ${ }^{16}$ Several studies have suggested that viral inoculum of SARS-CoV-2 could be associated with disease severity. ${ }^{17-19}$ Trials in humans to test this notion would be unethical, but animal studies suggest a dose-response relationship. ${ }^{20}$ The data presented in this study are the largest to date to support this theory.

In this study, we confirmed some obvious workplace risk factors for COVID-19 illness but not others. Reported increased frequency of exposure to patients with COVID-19 in the workplace was associated with higher risk of COVID-19 illness. Magnitude of risk was similar in those with at least very frequent exposure continuously at work as those who had episodic exposure to patients with COVID-19 without proper PPE. Interestingly, the number of shifts worked per week increased risk while the length of the shift did not. Perhaps this could be due to vulnerabilities when donning and doffing PPE in changing or transitional areas in the hospital. Alternatively, there could be risks in transportation to and from home to medical facilities for work. Paradoxically, in a basic model adjusting only for age, gender and country, high-risk procedures such as intubation or CPAP seemed to be associated with lower risk of COVID-19. However, after further adjustment for access to PPE and risk factors outside of the workplace, these associations became non-significant, suggesting that those providers who performed high-risk procedures may have had better access to PPE overall or at least during the high-risk procedures. 


\section{Strengths and limitations of study}

The study has several strengths, such as large sample size, inclusion of HCWs from multiple countries, and careful adjustment of potential confounders. Our study is also unique in that we were able to capture the period when many countries faced shortages of PPEs. At the time, healthcare system was ill prepared to meet the high PPE demands due to lack of inventories, ${ }^{21}$ leading to a gradient of access to PPE among HCWs.

This study has limitations that must be noted. Casecontrol studies have various limitations including recall bias regarding exposures. Additional factors that may be associated with COVID-19 illness could not be assessed such as local prevalence of COVID-19 and hospital infection control practices, including patient screening and testing practices. Like other observational studies, results herein represent statistical associations and cannot prove causality. Since randomised trials of PPE and COVID-19 among HCWs may not be ethical, data from prospective cohort studies should ideally be used to replicate our findings. We may have not included HCWs who may be considered high risk. ${ }^{22}$ However, our study focused on inpatient settings to have comparable cases and controls, and data on medical specialties at high risk of COVID-19 infection were not available at the time of study design. Furthermore, this study relied on participants' self-report of diagnosis, symptoms and test results as opposed to chart review. To restrict the study population to exposed HCWs, we used $>5 \%$ of time with patients with COVID19. However, this cut-off may be considered arbitrary and there is a possibility that HCWs may not be able to recall the time they had contact with patients with COVID-19 in the workplace. One study in medical students in UK in the setting of COVID-19 pandemic found that their self-reported level of PPE was not consistent with PPE supply. ${ }^{23}$ However, the consistent associations between access to PPE and COVID-19 across multiple countries lends credibility to our results. Future studies should validate self-reported level of PPE and PPE supply in HCWs. Next, we used ORs to estimate the associations between workplace risk factors and COVID-19. However, given how common COVID-19 is as of December 2020, our estimates based on ORs may overestimate the associations. Lastly, our study population mainly comprised middle-aged male physicians. Thus, our findings may not be generalisable to community settings or other groups of individuals, highlighting the need to build more evidence on PPE and COVID-19 in this area.

In conclusion, this study supports that inadequate access to PPE is a strong risk factor for preventing COVID-19 illness in front line workers, further underscoring the need for appropriate PPE. Mask, glove and gown changes for every patient encounter as well as a face shield was associated with the lowest risk for reporting symptoms consistent with COVID-19. Importantly, excellent access to PPE was also associated with shorter and less severe illness, supporting the idea that even when PPE fails, it may reduce viral inoculation.

\section{Author affiliations}

${ }^{1}$ Epidemiology, Johns Hopkins University Bloomberg School of Public Health, Baltimore, Maryland, USA

${ }^{2}$ Welch Center for Prevention, Epidemiology, and Clinical Research, Johns Hopkins University Bloomberg School of Public Health, Baltimore, MD, USA

${ }^{3}$ Cardiovascular Medicine, Brigham and Women's Hospital, Boston, MA, USA

${ }^{4}$ Harvard Medical School, Boston, MA, USA

${ }^{5}$ Envision Health Partners, Stamford, CT, USA

${ }^{6}$ Cardiology, Smidt Heart Institute, Cedars-Sinai Medical Center, Los Angeles, CA, USA

${ }^{7}$ Medicine, Stamford Hospital, Stamford, CT, USA

${ }^{8}$ Medicine, Columbia University College of Physicians and Surgeons, New York, NY, USA

Acknowledgements The authors thank all healthcare professionals involved in this study. They also thank John Turner and the team from Survey Healthcare Globus for their work and perseverance on this project.

Contributors SBS conceived the study. HK, SH, CF, MR and CR contributed to study design. CF and MR contributed to recruitment of health care professionals and data collection. HK, SC and SBS analysed the data. HK, SH, CF, MR, NS, SC and CR contributed to data interpretation. SBS drafted the manuscript and was involved in all aspects of the study from study design to interpretation. HK and SBS are the guarantors. All authors approved the final version of the manuscript.

Funding This work was funded by Survey Healthcare Globus. The funder was not involved in the analysis, interpretation of data, writing of the report, or decision to submit the article for publication. SC and NS received funding from the National Institutes of Health (U54-CA260591). HK and CMR are supported by grants from the National Heart, Lung, and Blood Institute (R21 HL143089; R56 HL153178) outside of the submitted work.

Map disclaimer The depiction of boundaries on this map does not imply the expression of any opinion whatsoever on the part of BMJ (or any member of its group) concerning the legal status of any country, territory, jurisdiction or area or of its authorities. This map is provided without any warranty of any kind, either express or implied.

Competing interests None declared.

\section{Patient consent for publication Not required.}

Ethics approval The study was approved by the WIRB IRB through Stamford Hospital, a teaching affiliate of Columbia College of Physicians and Surgeons. Informed consent was obtained electronically before the questionnaire was administered. The consent form contained language describing the nature of the research study and the subject's ability to refuse to participate without any loss of participation in other surveys. All of the risks (and benefits) associated with participation were delineated in the consent form.

Provenance and peer review Not commissioned; externally peer reviewed.

Data availability statement № data are available.

Supplemental material This content has been supplied by the author(s). It has not been vetted by BMJ Publishing Group Limited (BMJ) and may not have been peer-reviewed. Any opinions or recommendations discussed are solely those of the author(s) and are not endorsed by BMJ. BMJ disclaims all liability and responsibility arising from any reliance placed on the content. Where the content includes any translated material, BMJ does not warrant the accuracy and reliability of the translations (including but not limited to local regulations, clinical guidelines, terminology, drug names and drug dosages), and is not responsible for any error and/or omissions arising from translation and adaptation or otherwise.

Open access This is an open access article distributed in accordance with the Creative Commons Attribution Non Commercial (CC BY-NC 4.0) license, which permits others to distribute, remix, adapt, build upon this work non-commercially, and license their derivative works on different terms, provided the original work is properly cited, appropriate credit is given, any changes made indicated, and the use is non-commercial. See: http://creativecommons.org/licenses/by-nc/4.0/.

\section{REFERENCES}

1 Nguyen LH, Drew DA, Graham MS, et al. Risk of COVID-19 among front-line health-care workers and the general community: a prospective cohort study. Lancet Public Health 2020;5:e475-83. 
2 Adams JG, Walls RM. Supporting the health care workforce during the COVID-19 global epidemic. JAMA 2020;323:1439.

3 Lerner AM, Folkers GK, Fauci AS. Preventing the Spread of SARSCoV-2 With Masks and Other "Low-tech" Interventions. JAMA 1935;2020:324.

4 Chu DK, Akl EA, Duda S, et al. Physical distancing, face masks, and eye protection to prevent person-to-person transmission of SARS-CoV-2 and COVID-19: a systematic review and meta-analysis. Lancet 2020;395:1973-87.

5 Wang X, Ferro EG, Zhou G, et al. Association between universal masking in a health care system and SARS-CoV-2 positivity among health care workers. JAMA 2020;324:703.

6 Nagesh S, Chakraborty S. Saving the frontline health workforce amidst the COVID-19 crisis: challenges and recommendations. $J$ Glob Health 2020;10:010345.

7 Verbeek JH, Rajamaki B, ljaz S, et al. Personal protective equipment for preventing highly infectious diseases due to exposure to contaminated body fluids in healthcare staff. Cochrane Database Syst Rev 2020;4:CD011621.

8 Bundgaard H, Bundgaard JS, Raaschou-Pedersen DET, et al Effectiveness of Adding a Mask Recommendation to Other Public Health Measures to Prevent SARS-CoV-2 Infection in Danish Mask Wearers : A Randomized Controlled Trial. Ann Intern Med 2020. doi:10.7326/M20-6817. [Epub ahead of print: 18 Nov 2020].

9 Worldometer. Coronavirus graphs: worldwide cases and deaths. Available: https://www.worldometers.info/coronavirus/worldwidegraphs/ [Accessed 27 Dec 2020].

10 Heinzerling A, Stuckey MJ, Scheuer T, et al. Transmission of COVID-19 to health care personnel during exposures to a hospitalized patient - Solano County, California, February 2020. MMWR Morb Mortal Wkly Rep 2020:69:472-6.

11 Wang X, Pan Z, Cheng Z. Association between 2019nCoV transmission and N95 respirator use. $J$ Hosp Infect 2020:105:104-5.

12 Wang Q, Huang X, Bai Y. Epidemiological characteristics of COVID-19 in medical staff members of neurosurgery departments in Hubei Province: a multicentre descriptive study. medRxiv2020:2020.04.20.20064899.
13 Wang Y, Tian $\mathrm{H}$, Zhang L, et al. Reduction of secondary transmission of SARS-CoV-2 in households by face mask use, disinfection and social distancing: a cohort study in Beijing, China. BMJ Glob Health 2020;5.

14 Chou R, Dana T, Jungbauer R, et al. Masks for Prevention of Respiratory Virus Infections, Including SARS-CoV-2, in Health Care and Community Settings : A Living Rapid Review. Ann Intern Med 2020;173:542-55.

15 Leung NHL, Chu DKW, Shiu EYC, et al. Respiratory virus shedding in exhaled breath and efficacy of face masks. Nat Med 2020;26:676-80.

16 Gandhi M, Beyrer C, Goosby E. Masks do more than protect others during COVID-19: reducing the inoculum of SARS-CoV-2 to protect the wearer. J Gen Intern Med 2020;35:3063-6.

17 Gandhi M, Rutherford GW. Facial Masking for Covid-19 - Potential for "Variolation" as We Await a Vaccine. N Engl J Med Overseas Ed 2020;383:e101.

18 Bielecki M, Züst R, Siegrist D, et al. Social distancing alters the clinical course of COVID-19 in young adults: a comparative cohort study. Clin Infect Dis 2020. doi:10.1093/cid/ciaa889. [Epub ahead of print: 29 Jun 2020].

19 Guallar MP, Meiriño R, Donat-Vargas C, et al. Inoculum at the time of SARS-CoV-2 exposure and risk of disease severity. Int $\mathrm{J}$ Infect Dis 2020;97:290-2.

20 Imai M, Iwatsuki-Horimoto $\mathrm{K}$, Hatta $\mathrm{M}$, et al. Syrian hamsters as a small animal model for SARS-CoV-2 infection and countermeasure development. Proc Natl Acad Sci U S A 2020;117:16587-95.

21 Cohen J, Rodgers YvanderM. Contributing factors to personal protective equipment shortages during the COVID-19 pandemic. Prev Med 2020;141:106263.

22 Bandyopadhyay S, Baticulon RE, Kadhum M, et al. Infection and mortality of healthcare workers worldwide from COVID-19: a systematic review. BMJ Glob Health 2020;5:e003097.

23 Norton EJ, Georgiou I, Fung A, et al. Personal protective equipment and infection prevention and control: a national survey of UK medical students and interim Foundation doctors during the COVID-19 pandemic. J Public Health 2020. doi:10.1093/pubmed/ fdaa187. [Epub ahead of print: 23 Oct 2020]. 